\title{
The prevalence of human papillomavirus and its impact on cervical dysplasia in Northern Canada
}

Ying Jiang ${ }^{1}$, Paul Brassard ${ }^{2}$, Alberto Severini ${ }^{3}$, Yang Mao ${ }^{1}$, Y Anita $\mathrm{Li}^{4}$, Julie Laroche ${ }^{4}$, Susan Chatwood ${ }^{5}$, Andre Corriveau ${ }^{6}$, Kami Kandola ${ }^{6}$, Brendan Hanley ${ }^{7}$, Isaac Sobol ${ }^{8}$, Muna Ar-Rushdi ${ }^{9}$, Gordon Johnson ${ }^{10}$, Jane Lo ${ }^{11}$, Sam Ratnam ${ }^{12}$, Tom Wong ${ }^{13}$, Alain Demers ${ }^{13}$, Gayatri Jayaraman ${ }^{13}$, Stephanie Totten ${ }^{13}$ and Howard Morrison ${ }^{1 *}$

\begin{abstract}
Introduction: Certain types of the Human Papillomavirus (HPV) are sexually transmitted and highly associated with development of cervical dysplasia and cervical cancer but the distribution of HPV infection in the North, particularly amongst First Nations, Metis, and Inuit peoples, is little known. The purposes of the study are to identify the prevalence of type-specific HPV infections and the association of different HPV types with cervical dysplasia among women in Northern Canada.

Methods: This was a cross-sectional study with attendants of the routine or scheduled Pap testing program in the Northwest Territories (NWT), Nunavut, Labrador and Yukon, Canada. Approximately half of each sample was used for Pap test and the remaining was used for HPV genotyping using a Luminex-based method. Pap test results, HPV types, and demographic information were linked for analyses.

Results: Results from 14,598 specimens showed that HPV infection was approximately $50 \%$ higher among the Aboriginal than the non-Aboriginal population (27.6\% vs. 18.5\%). Although the most common HPV type detected was HPV 16 across region, the prevalence of other high risk HPV types was different. The age-specific HPV prevalence among Aboriginal showed a ' $U$ ' shape which contrasted to non-Aboriginal. The association of HPV infection with cervical dysplasia was similar in both Aboriginal and non-Aboriginal populations.

Conclusions: The HPV prevalence was higher in Northern Canada than in other Areas in Canada. The prevalence showed a higher rate of other high risk HPV infections but no difference of HPV 16/18 infections among Aboriginal in comparison with non-Aboriginal women. This study provides baseline information on HPV prevalence that may assist in surveillance and evaluation systems to track and assess HPV vaccine programs.
\end{abstract}

Keywords: Human papillomavirus, Prevalence, Pap abnormality, Northern region

\section{Introduction}

Cervical cancer is the second most common cancer of the women worldwide. In Canada invasive cervical cancer and associated mortality among Aboriginal women have been 2-4 times higher than among non-Aboriginal women [1-4]. From the Statistics Canada 2006 census Aboriginal groups make up more than $50 \%$ of the population in the Northwest Territories (NWT) [5] (First Nations, Metis, and Inuit), $85 \%$ of the population in Nunavut [6] (predominantly Inuit), 35\% in Labrador [7] (Metis, Inuit, and

\footnotetext{
* Correspondence: Howard.Morrison@phac-aspc.gc.ca

${ }^{1}$ Science Integration Division, Public Health Agency of Canada (PHAC), 785 Carling Ave., Ottawa, ON K1A OK9, Canada

Full list of author information is available at the end of the article
}

First Nations), and 25\% in the Yukon [8] (predominantly First Nations). Increased risk of cervical cancer in Aboriginal women has been consistently observed in various regions across Northern Canada $[2,9,10]$. The gap in cervical cancer and associated mortality between the Aboriginal and non-Aboriginal groups has important implications for cancer control policy. Implementation and evaluation of cervical cancer prevention programs in Aboriginal women may require a different approach.

Human Papillomavirus (HPV) is a common sexually transmitted infection worldwide. Persistent infection with specific types of the virus is necessary for the development of invasive cervical cancer and its precursor lesions [11]. HPV is detected in almost $100 \%$ of women with invasive 
cervical cancer and types 16 and 18 are responsible for approximately $70 \%$ of all cases $[12,13]$. In Canada HPV $16 / 18$ prevalence has been reported in $56.2 \%$ of high grade precursor lesions [14]. HPV 16/18 prevalence can vary by geography and ethnicity. Therefore, determination of type-specific HPV prevalence in a region may be one of the important steps towards cervical cancer prevention.

Only very limited regional data $[2,3,15]$ provide HPV prevalence in Northern Canada which appears different with that of the general population. Population based research on HPV and related outcomes in the North could fill this information gap. For cervical cancer prevention and early detection of pre-cancerous lesions, routine Papanicolaou smear (Pap) test screening is offered in all regions of Northern Canada with good coverage of targeted population. In $2008,88 \%, 74 \%, 83 \%$, and $81 \%$ of women aged 18-69 in NWT, Nunavut, Labrador, and Yukon respectively, were reported as having had a Pap test in the previous three years [16]. It was therefore considered a practical and efficient approach to examine HPV prevalence as part of routine Pap smear screening.

The purpose of this study is to measure the prevalence of HPV infections by type and region and to determine their impacts on cervical dysplasia across Northern Canada.

\section{Methods}

\section{Study population}

This was a cross-sectional study including all women aged 14 years or older who presented for a regular Pap test in the four regions of Northern Canada: NWT (April, 2008 March, 2009), Nunavut (January, 2008 - March, 2009), Labrador (February - November, 2010), and Yukon (March, 2009 - June, 2010). Women with a cervical cancer history and those who chose to opt-out were excluded from the study. Only the first sample collected was kept for analysis for women with more than one Pap smear performed over the study period. An opt-in consent process was used in Yukon which was different with the other jurisdictions. Given the universal coverage of the health care system in Canada there are no other Pap test providers in these areas.

\section{Authority and licensing}

This research received ethical approval from the Health Canada Ethics Review Board, McGill University Ethics Review, and the local health authorities including NWT Department of Health and Social Services, Stanton Territorial Health Authority, the Yukon Department of Health and Social Services, and the Yukon Scientists and Explorers Act License. A Northern research licence was also obtained from Aurora Research Institute in the NWT. The project was facilitated by four data collection sites and the manuscript was reviewed by community stakeholders before being submitted for publication.

\section{Data source}

Pap test screening is performed in each Territory and the Labrador health region in Canada. It is offered to all women aged 18-69 and young women aged 14-18 who wish to participate. Pap smears are collected at community health centres, medical clinics, or hospitals whichever appropriate. Pap test registration form is used to assemble personal record and demographic information on site. Demographic details including Aboriginal status, age, and region information were abstracted from the routine Pap test registration form. Aboriginal status was only available among NWT, Nunavut, and Yukon datasets. Only area code (residence in Aboriginal area or non-Aboriginal area) was available in the Labrador dataset. Data were collected, organised, and owned by the local health authorities.

\section{Specimen collection and preparation}

Samples from NWT and Nunavut were collected in liquid based cytology (LBC) medium (SurePath ${ }^{\circledR}$ ) and were shipped to the DynaLife Medical Laboratory in Edmonton, where cytology was read and remaining half of the specimen was kept for HPV testing. Samples from Labrador were also collected in SurePath LBC medium and shipped to Newfoundland Public Health Laboratory for Pap test interpretation. In Yukon, conventional Pap smear slides were taken and shipped to the Cervical Cancer Screening Laboratory, BC Cancer Control Agency. A sample for HPV testing was prepared by taking a second cervical sample and by rinsing the brushes in LBC medium. Samples for HPV genotyping were shipped from all four areas to the National Microbiology Laboratory (NML) in Winnipeg, Canada. Cervical cytology and HPV testing were done independently to eliminate the potential for reporter bias.

\section{HPV typing}

For HPV genotyping an "in house" Luminex assay [17] developed at the NML was used. This assay detects 45 high risk and low risk HPV types. Comparison against the Linear Array (Roche) [17] and other HPV genotyping kits [18] showed that this Luminex assay is comparable to other commercial genotyping methods. The $45 \mathrm{HPV}$ types included 23 of the 25 IARC high risk (HR) types found in group 1, 2a, and $2 \mathrm{~b}$ (HPV 16, 18, 26, 30, 31, 33, $35,39,45,51,52,53,56,58,59,66,67,68,69,70,73,82$ and 85) [19], and other 22 types considered of low (LR) or unknown risk $(6,11,13,32,40,42,43,44,54,61,62$, $71,72,74,81,83,84,86,87,89,90$, and 91) [19].

\section{Pap smear testing}

Cytological reports were issued according to the Bethesda system [20,21]. The results were classified as: normal (including benign), atypical squamous cells of undetermined significance (ASC-US), low-grade squamous intraepithelial 
Table 1 HPV type distribution by cytological results in Northern Canada ${ }^{1}$

\begin{tabular}{|c|c|c|c|c|c|c|}
\hline \multirow[t]{2}{*}{$\mathrm{HPV}^{2}$ typing } & \multicolumn{4}{|c|}{ Cytological results $^{3}$} & \multicolumn{2}{|c|}{ Total } \\
\hline & Normal & ASC-US & LSIL & $\mathrm{HSIL}+\mathrm{ASC}-\mathrm{H}$ & $n$ & $\%$ \\
\hline HPV negative & 10488 & 92 & 46 & 19 & 10645 & $74.1 \%$ \\
\hline HPV positive & 2891 & 320 & 372 & 145 & 3728 & $25.9 \%$ \\
\hline Total & 13379 & 412 & 418 & 164 & 14373 & $100.0 \%$ \\
\hline \multicolumn{7}{|l|}{ HR-HPV } \\
\hline $16^{3}$ & 485 & 79 & 85 & 71 & 720 & $5.0 \%$ \\
\hline 31 & 236 & 44 & 31 & 17 & 328 & $2.3 \%$ \\
\hline 66 & 172 & 30 & 50 & 2 & 254 & $1.8 \%$ \\
\hline 45 & 171 & 27 & 23 & 10 & 231 & $1.6 \%$ \\
\hline 59 & 179 & 20 & 26 & 6 & 231 & $1.6 \%$ \\
\hline 18 & 141 & 32 & 41 & 10 & 224 & $1.6 \%$ \\
\hline 51 & 151 & 17 & 47 & 4 & 219 & $1.5 \%$ \\
\hline 39 & 153 & 18 & 40 & 8 & 219 & $1.5 \%$ \\
\hline 58 & 148 & 21 & 27 & 15 & 211 & $1.5 \%$ \\
\hline 67 & 142 & 16 & 18 & 6 & 182 & $1.3 \%$ \\
\hline 52 & 132 & 21 & 13 & 12 & 178 & $1.2 \%$ \\
\hline 70 & 131 & 12 & 21 & 2 & 166 & $1.2 \%$ \\
\hline 56 & 99 & 8 & 36 & 5 & 148 & $1.0 \%$ \\
\hline 33 & 94 & 15 & 24 & 9 & 142 & $1.0 \%$ \\
\hline 35 & 85 & 9 & 16 & 11 & 121 & $0.8 \%$ \\
\hline 73 & 59 & 6 & 10 & 1 & 76 & $0.5 \%$ \\
\hline 53 & 48 & 7 & 18 & 1 & 74 & $0.5 \%$ \\
\hline 68 & 35 & 3 & 4 & 1 & 43 & $0.3 \%$ \\
\hline 30 & 20 & 7 & 5 & 0 & 32 & $0.2 \%$ \\
\hline 69 & 24 & 2 & 4 & 0 & 30 & $0.2 \%$ \\
\hline 85 & 24 & 3 & 3 & 0 & 30 & $0.2 \%$ \\
\hline 82 & 11 & 2 & 5 & 0 & 18 & $0.1 \%$ \\
\hline 26 & 3 & 2 & 3 & 1 & 9 & $0.1 \%$ \\
\hline Total & 2743 & 401 & 550 & 192 & 3886 & $27.0 \%$ \\
\hline \multicolumn{7}{|l|}{ LR-HPV } \\
\hline 42 & 159 & 10 & 14 & 2 & 185 & $1.3 \%$ \\
\hline 62 & 158 & 9 & 7 & 0 & 174 & $1.2 \%$ \\
\hline 81 & 129 & 12 & 11 & 2 & 154 & $1.1 \%$ \\
\hline 6 & 112 & 16 & 22 & 1 & 151 & $1.1 \%$ \\
\hline 89 & 107 & 9 & 9 & 0 & 125 & $0.9 \%$ \\
\hline 72 & 101 & 2 & 3 & 1 & 107 & $0.7 \%$ \\
\hline 54 & 94 & 3 & 9 & 0 & 106 & $0.7 \%$ \\
\hline 83 & 75 & 4 & 6 & 0 & 85 & $0.6 \%$ \\
\hline 84 & 70 & 7 & 3 & 0 & 80 & $0.6 \%$ \\
\hline 40 & 55 & 6 & 6 & 2 & 69 & $0.5 \%$ \\
\hline 74 & 62 & 6 & 1 & 0 & 69 & $0.5 \%$ \\
\hline 90 & 53 & 2 & 12 & 0 & 67 & $0.5 \%$ \\
\hline 86 & 43 & 3 & 1 & 0 & 47 & $0.3 \%$ \\
\hline 11 & 27 & 9 & 8 & 0 & 44 & $0.3 \%$ \\
\hline
\end{tabular}


Table 1 HPV type distribution by cytological results in Northern Canada ${ }^{1}$ (Continued)

\begin{tabular}{|c|c|c|c|c|c|c|}
\hline 44 & 48 & 1 & 0 & 0 & 49 & $0.3 \%$ \\
\hline 43 & 15 & 2 & 5 & 1 & 23 & $0.2 \%$ \\
\hline 32 & 19 & 1 & 0 & 1 & 21 & $0.1 \%$ \\
\hline 87 & 18 & 0 & 1 & 0 & 19 & $0.1 \%$ \\
\hline 13 & 10 & 3 & 2 & 0 & 15 & $0.1 \%$ \\
\hline 61 & 9 & 1 & 0 & 0 & 10 & $0.1 \%$ \\
\hline 91 & 2 & 1 & 5 & 0 & 8 & $0.1 \%$ \\
\hline 71 & 1 & 0 & 0 & 0 & 1 & $0.0 \%$ \\
\hline Total & 1367 & 107 & 125 & 10 & 1609 & $11.2 \%$ \\
\hline
\end{tabular}

lesion (LSIL), and high-grade squamous intraepithelial lesion (HSIL). Samples with atypical squamous cells (ASC-H), where HSIL could not be excluded, were added to the HSIL category. To be consistent with reported data worldwide we classified LSIL and HSIL as abnormal categories for the correlation analysis and impact assessment. ASCUS cases were not included in this part of analysis.

\section{Statistical analyses}

\section{Data preparation}

Demographic information, HPV types and Pap test results were linked for HPV prevalence analysis. In the linkage dataset, 764 records (approximately 5\% of collected data in the study) with one or more items of missing value were excluded from the analysis; 485 missing in age or age-group, 327 in ethnic status or ethnic area, and 399 in Pap test including 126 unsatisfactory cytology results.

HPV_s and HR_s were defined as cases with only a single type of HPV infection and cases with only a single type of high risk HPV infection, respectively. Similarly, HPV_m and HR_m were defined as samples with two or more types of HPV or HR HPV infection. Samples with two or more HPV types were counted in for each type in type-specific analysis.

\section{Analysis}

Prevalence rates for type-specific HPV infection and cervical dysplasia were computed. Based on the 2008 census data among women in the NWT region [5] as the standard, the age-adjusted prevalence rates (AAPR) were calculated for area comparison. The overall prevalence rate in Northern Canada was also weighted by population size [5-8] by region.

A multivariate logistic regression analysis was used to explore the associations between HPV infection and cervical dysplasia, adjusted for Aboriginal status, age, and region. Odd Ratios (ORs) were calculated by different level: (a) infection with any HPV type, single HR infection, multiple HR infection, single LR infection, multiple LR infection, and infection with both LR and HR types, relative to no HPV infection, and (b) infection with both HR and LR HPV types relative to a single LR HPV infection.

The proportion of cervical dysplasia caused by HPV infection in Northern Canada was measured by the exposure attributable risk fraction (ARF) and the population attributable risk fraction (PAR). In calculating the PAR, to avoid duplicate counting of those infected with both HR and LR, the exposed population was first stratified into those infected with only HR, only LR, and both. The PARs were summed across the strata. ORs are used in the calculation of both ARF and PAR: ARF $=(\mathrm{OR}-1) /$ $\mathrm{OR}$ and $\mathrm{PAR}=($ Number of exposed cases $\mathrm{x}$ ARF $) /$ total cases in the population. Furthermore, PAR of HR HPV infection $=$ (No. of HR_s cases $\mathrm{x}$ ARF reference to HPV negative + No. of only multiple HR cases $x$ ARF reference to HPV negative + No. of both HR and LR infected cases $\mathrm{x}$ ARF reference to LR HPV) / total cases [22].

All data management and analyses were carried out using Statistical Analysis System 9.1. Two-tailed p value $<0.05$ was the criteria to determine the statistical significant [23].

\section{Results}

A total of 14598 cytology samples were collected and tested from NWT ( $\mathrm{n}=6940)$, Nunavut $(\mathrm{n}=4683)$, Labrador $(\mathrm{n}=1370)$, and the Yukon $(\mathrm{n}=1605)$. In NWT and Nunavut the study covered more than $95 \%$ of the Program targeted population, respectively; but only $77 \%$ and $27 \%$ in Labrador and the Yukon in the study period. In this study, approximately $42 \%$ of women were nonAboriginal and 58\% were Aboriginal. The overall mean 
and median ages of participants were 35 and 32 , respectively.

\section{HPV prevalence analysis}

\section{Type specific}

HPV-DNA was detected in $26 \%$ of subjects (Table 1 ). After weighting the four regional population sizes from census data, the overall prevalence rate in Northern Canada was estimated to be $25.2 \%$. Although the specific prevalence of HPV types was dissimilar among regions, the highest prevalence HPV types detected were HPV-16 (5.0\%), HPV-31 (2.3\%), HPV-66 (1.8\%), HPV-45 (1.6\%), HPV-59 (1.6\%), and HPV-18 (1.6\%). HPV type distributions are different by region (Figure 1). Among HPV infected samples, $79 \%$ had an HR type, 33\% had multi-types, and 25\% had HPV 16/18. The overall prevalence of HPV_m, HR_s, HR_m, and LR_s were $8.4 \%, 13 \%$, $4.0 \%$, and $4.7 \%$, respectively.

\section{Age specific}

The age specific HPV prevalence rate ranged between $13 \%$ and $48 \%$ (Figure 2). The highest prevalence of HR HPV infection and HPV 16/18 was among women aged less than 20 years, with decreasing prevalence until age group 40-49. HPV prevalence was higher in the Aboriginal than the non-Aboriginal women in each age group;

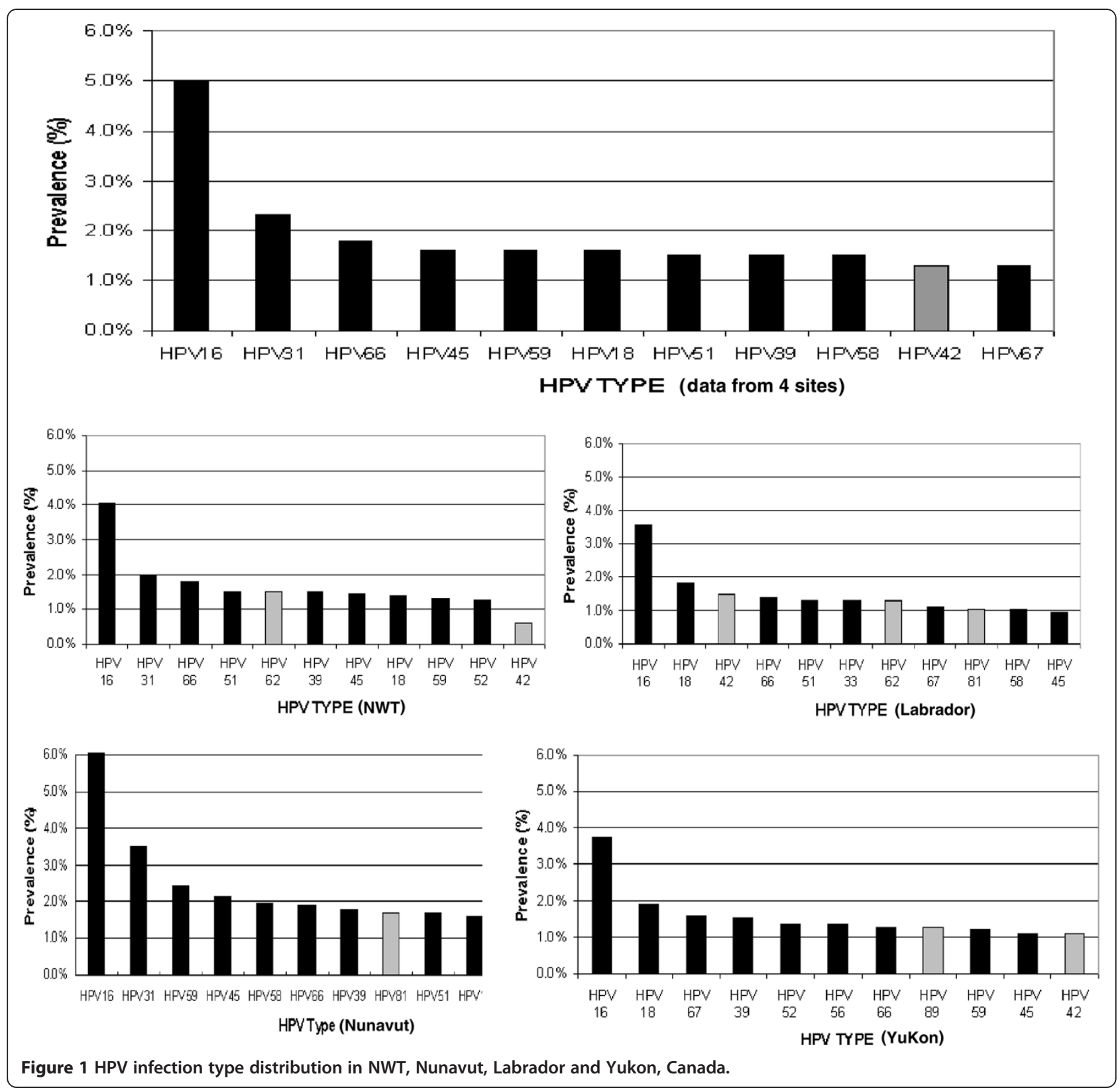




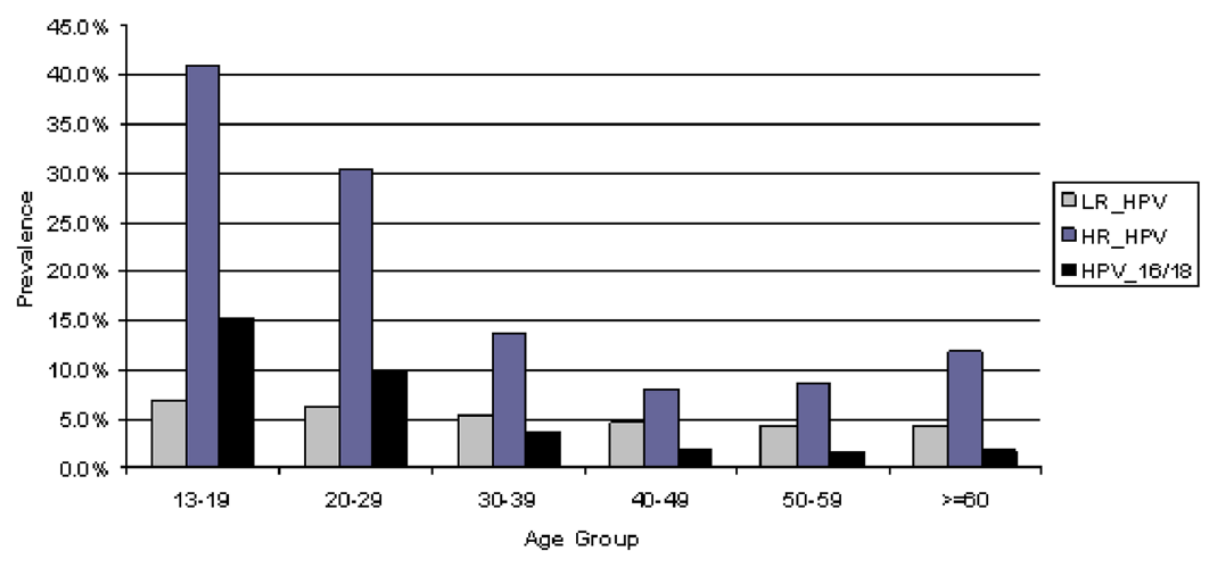

Figure 2 Proportion of HPV types by agegroup, in NWT, Nunavut, Labrador and Yukon, Canada.

in particular among women aged 50 or over (Figure 3). It is of note on the trend that the prevalence of HPV increased again after age 50 thus forming a U-shaped curve in the Aboriginal women, but following a monotonic decrease with age in the non-Aboriginal women.

\section{Regional and ethnic differences in HPV prevalence}

In Table 2, HPV prevalence rate in NWT, Nunavut, Labrador, and Yukon was $23.2 \%, 31.5 \%, 21.4 \%$, and $24.5 \%$; respectively. After adjusting by the NWT 2008 census data for women as a standard population AAPRs changed to $22.7 \%, 28.0 \%, 21.1 \%$, and 23.5\%; respectively. Any type HPV and HR type HPV AAPRs were significantly higher among the Aboriginal than the non-Aboriginal women. However the HPV 16/18 AAPRs were not statistically different by ethnic group across region. In addition the HR HPV prevalence rates accounted for a higher percentage in any HPV infection among the Aboriginal than among the non-Aboriginal population. HPV 16/18 comprised about $30 \%$ of all HR-HPV infection in all four regions.

\section{Prevalence by Pap test results}

Overall, $4.0 \%$ of Pap test results were abnormal (HSIL and LSIL); $4.7 \%$ in Aboriginal and $3.1 \%$ in nonAboriginal group (Table 3). Among the women with normal cytology (92.3\%), the HPV prevalence rate in the Aboriginal was $26 \%$ in comparison to $15 \%$ of the nonAboriginal group. However, among women with abnormal Pap test, the HPV prevalence was $91.6 \%$ in the Aboriginal versus $82.9 \%$ in the non-Aboriginal group. Stratified analyses on HPV infection by cytological results in women aged $<30$ and aged 30 or over among the Aboriginal and the non-Aboriginal showed that distributions of HPV prevalence by cytological result were similar in different ethnic and age groups. In particular, the relative prevalence of HPV 16/18 among HSIL was not significantly different in Aboriginal (46.9) vs Non-Aboriginal women (50.0), as shown in Table 3 . Among women with normal cytology 419 (5.4\%) and 182 (3.4\%) were infected with HPV 16/18 in the Aboriginal and non-Aboriginal group, respectively. The corresponding numbers for HR HPV other than 16/18

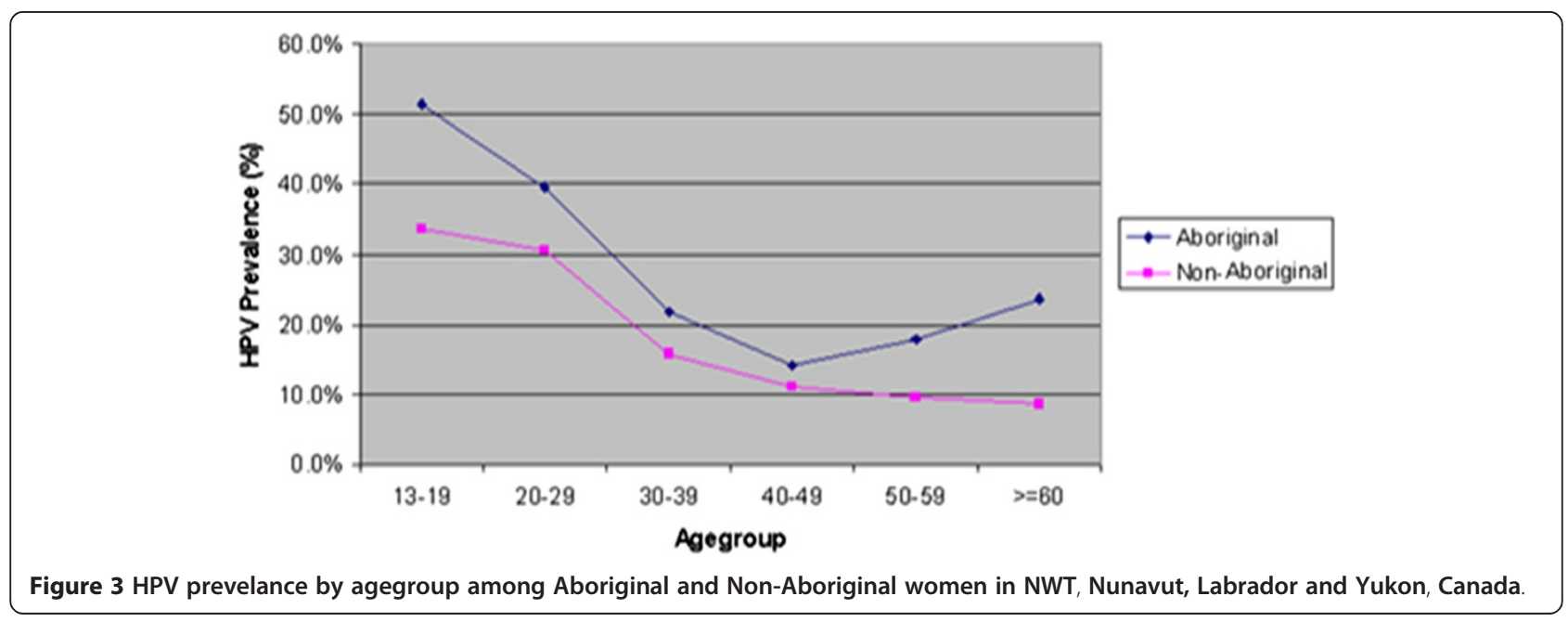


Table 2 HPV infection prevalence rate among women in Northern Canada, 2008-2010

\begin{tabular}{|c|c|c|c|c|c|c|c|c|c|c|}
\hline \multirow[t]{3}{*}{ Region } & \multirow[t]{3}{*}{$\#$} & \multicolumn{3}{|c|}{ Any type } & \multicolumn{3}{|c|}{ HR_HPV } & \multicolumn{3}{|c|}{ HPV 16/18 } \\
\hline & & $\#$ & $\%$ & $\mathrm{AAPR}^{*}$ & $\#$ & $\%$ & AAPR & \# & $\%$ & AAPR \\
\hline & & & & $(95 \% \mathrm{Cl})$ & & & $(95 \% \mathrm{Cl})$ & & & $(95 \% \mathrm{Cl})$ \\
\hline NWT & 6724 & 1561 & 23.2 & $22.7(21.5,24.0)$ & 1205 & 17.9 & $17.5(16.5,18.6)$ & 352 & 5.2 & $4.9(4.4,5.5)$ \\
\hline Nunavut & 4654 & 1468 & 31.5 & $28.0(26.3,29.6)$ & 1205 & 25.9 & $22.2(20.8,23.7)$ & 387 & 8.3 & $4.5(2.8,6.3)$ \\
\hline Labrador $^{* *}$ & 1370 & 293 & 21.4 & $21.1(18.6,23.6)$ & 218 & 15.9 & $15.8(13.6,18.0)$ & 73 & 5.3 & $5.5(4.2,6.8)$ \\
\hline Yukon & 1542 & 378 & 24.5 & $23.5(20.9,26.1)$ & 284 & 18.4 & $17.7(15.4,19.9)$ & 96 & 6.2 & $6.0(4.7,7.3)$ \\
\hline Aboriginal & 8446 & 2623 & 31.1 & $27.6(25.5,29.8)$ & 2104 & 24.9 & $21.6(19.7,23.5)$ & 630 & 7.5 & $6.1(5.1,7.0)$ \\
\hline Non-Aboriginal & 5844 & 1077 & 18.4 & $18.5(16.2,20.8)$ & 808 & 13.8 & $13.8(11.8,15.7)$ & 278 & 4.8 & $4.9(3.9,6.0)$ \\
\hline$P^{* * *}$ & & & & $<0.01$ & & & $<0.01$ & & & $>0.05$ \\
\hline
\end{tabular}

*AAPRs (Age-Adjusted Prevalence Rates) were calculated using NWT 2008 standard population.

** Labrador data only had area code (residence in Aboriginal area or not) instead of Aboriginal Status information.

${ }^{* * *} \mathrm{P}$-value is tested for significant difference between Aboriginal and Non-Aboriginal women in each site using Chi-square test.

infection were 1107 (14.4\%) and 401 (7.4\%), while the numbers for all HPV infection were 2004 (26\%) and 829 (15\%), respectively.

\section{Impact of HPV on cervical abnormalities}

After adjusting for Aboriginal status, age, and region, the logistic regression models showed that the ORs for cervical abnormalities associated with any type HPV, LR_s, HR_s, only multiple LR infections, only multiple HR infections and mixed HR and LR infections were 28.9, 5.3, 29.4, 6.2, 71.9, and 35.4, respectively, and that HPV infection accounted for $85.7 \%$ of the cervical abnormalities with $80.6 \%$ attributable to high risk HPV infection and 32.5\% attributable to HPV 16/18 infection (Table 4).

\section{Discussions}

This study recruited most of the women aged 18-69 (and most of the incidental consultations for the 14-17 age group) who attended routine or scheduled pap screening over an approximately one year time period.

The prevalence of overall HPV infection was 25.2\% which was higher than in most countries [24-27] but similar to Denmark [28] and the US [29]. HPV prevalence rates in both the Aboriginal (31.6\%) and nonAboriginal women (18.9\%) in this study were slightly higher than those in other studies in Aboriginal $[2,15]$ and non-Aboriginal $[30,31]$ populations in Canada. The proportion of HR types among the HPV-positive women was lower than in British Columbia and Ontario studies but higher than in a Quebec study [2,30,31].

Table 3 Cytological results by HPV types in Northern Canada

\begin{tabular}{|c|c|c|c|c|c|c|c|c|c|c|c|c|c|c|}
\hline \multirow[t]{2}{*}{ Cytology ${ }^{*}$} & \multicolumn{2}{|c|}{ Overall } & \multicolumn{2}{|c|}{ Any type } & \multicolumn{2}{|c|}{ HR_HPV } & \multicolumn{2}{|c|}{ LR_HPV } & \multicolumn{2}{|c|}{ HPV_m } & \multicolumn{2}{|c|}{ HR_m } & \multicolumn{2}{|c|}{ HPV 16/18 } \\
\hline & $\mathrm{N}$ & $\%^{* *}$ & $\mathrm{~N}$ & $\%^{* * *}$ & $\mathrm{~N}$ & $\%^{* * *}$ & $\mathrm{~N}$ & $\%^{* * *}$ & $\mathbf{N}$ & $\%^{* * *}$ & $\mathrm{~N}$ & $\%^{* * *}$ & $\mathrm{~N}$ & $\%^{* * *}$ \\
\hline Aboriginal & 8428 & 100 & 2617 & 31.1 & 2098 & 24.9 & 219 & 2.6 & 885 & 10.5 & 418 & 5.0 & 626 & 7.4 \\
\hline Normal & 7693 & 91.3 & 2004 & 26.0 & 1526 & 19.8 & 478 & 6.2 & 617 & 8.0 & 261 & 3.4 & 419 & 5.4 \\
\hline ASC-US & 294 & 3.5 & 241 & 82.0 & 219 & 74.5 & 22 & 7.5 & 92 & 31.3 & 48 & 16.3 & 77 & 26.2 \\
\hline LSIL & 279 & 3.3 & 256 & 91.8 & 239 & 85.7 & 17 & 6.1 & 142 & 50.9 & 83 & 29.7 & 73 & 26.2 \\
\hline HSIL & 113 & 1.3 & 103 & 91.2 & 103 & 91.2 & 0 & 0.0 & 28 & 24.8 & 24 & 21.2 & 53 & 46.9 \\
\hline unsatisfactory & 49 & 0.6 & 13 & 26.5 & 11 & 22.4 & 2 & 4.1 & 6 & 12.2 & 2 & 4.1 & 4 & 8.2 \\
\hline Non-Aboriginal & 5765 & 100 & 1060 & 18.4 & 795 & 13.8 & 265 & 4.6 & 313 & 5.4 & 148 & 2.6 & 272 & 4.7 \\
\hline Normal & 5404 & 93.7 & 829 & 15.3 & 583 & 10.8 & 246 & 4.6 & 219 & 4.1 & 89 & 1.6 & 182 & 3.4 \\
\hline ASC-US & 110 & 1.9 & 72 & 65.5 & 64 & 58.2 & 8 & 7.3 & 30 & 27.3 & 19 & 17.3 & 26 & 23.6 \\
\hline LSIL & 133 & 2.3 & 110 & 82.7 & 103 & 77.4 & 7 & 5.3 & 46 & 34.6 & 27 & 20.3 & 38 & 28.6 \\
\hline HSIL & 48 & 0.8 & 40 & 83.3 & 39 & 81.3 & 1 & 2.1 & 16 & 33.3 & 13 & 27.1 & 24 & 50.0 \\
\hline unsatisfactory & 70 & 1.2 & 9 & 12.9 & 6 & 8.6 & 3 & 4.3 & 2 & 2.9 & 0 & 0.0 & 2 & 2.9 \\
\hline
\end{tabular}

Note:

*3 records with suspicious or malignant carcinoma are not involved in the table.

** Overall shown column percentage.

${ }^{* * *}$ Type specifics shown row Percentage. 
Table 4 Logistic regression analysis of the association between HPV infection and cervical abnormality in NWT, Nunavut, Labrador and Yukon, Canada

\begin{tabular}{|c|c|c|c|c|c|c|}
\hline & \multirow{2}{*}{$\begin{array}{c}\text { HPV } \\
\text { Infection }\end{array}$} & \multicolumn{2}{|c|}{ Pap test results } & \multirow{2}{*}{$\begin{array}{c}\text { Adjusted OR } \\
(95 \% \mathrm{Cl})\end{array}$} & \multirow[t]{2}{*}{ ARF } & \multirow[t]{2}{*}{ PAF } \\
\hline & & Normal & LSIL/HSIL & & & \\
\hline \multirow[t]{9}{*}{$\overline{\text { Ref. }}$} & HPV Negative & 10488 & 65 & & & \\
\hline & Any Type HPV & 2891 & 517 & $28.89(22.24,37.53)$ & 96.5 & 85.7 \\
\hline & Single-HR & 1413 & 260 & $29.45(22.30,38.90)$ & 96.6 & 43.2 \\
\hline & Single-LR & 630 & 21 & $5.30(3.22,8.74)$ & 81.1 & 2.9 \\
\hline & Multiple-HR & 354 & 151 & $71.93(52.55,98.47)$ & 98.6 & 25.6 \\
\hline & Multiple-LR & 114 & 4 & $6.16(2.19,17.31)$ & 83.8 & 0.6 \\
\hline & HR/LR mix & 380 & 81 & $35.35(25.01,49.98)$ & 97.2 & 13.5 \\
\hline & Total & 13379 & 582 & & & \\
\hline & HPV16 or 18 & 614 & 193 & $50.82(37.85,68.23)$ & 98.0 & 32.5 \\
\hline \multirow[t]{3}{*}{ Ref. } & Single-LR & 630 & 21 & & & \\
\hline & $\mathrm{HR} / \mathrm{LR}$ mix & 380 & 81 & $6.47(3.93,10.66)$ & 84.5 & 11.8 \\
\hline & & & & PAR for HR HPV infection: 80.6 & & \\
\hline
\end{tabular}

Multiple-HR is HR multiple only.

Adjusted model is adjusted using Age-group, Region, and Aboriginal status. (Labrador is using Aboriginal Area as Aboriginal variables).

Similar to most European and Canadian studies the two most common HPV types detected in Northern Canada were HPV-16 and 31 [28,32-36]. The HPV 16/18 prevalence in the study was relatively lower than all similar studies in Canada [2,30,31,35], but comparable to studies in Europe and the US $[25,26,28,29,37]$. In this study HPV $16 / 18$ comprised about $31 \%$ of all HR-HPV infections. Several HR HPV types other than HPV 16/18, such as HPV 31, 39, 45, 51,59 and 66 were relatively common in Northern Canada.

The prevalence analysis shows that HPV prevalence was highest among women aged less than 20 years, which is consistent with other studies [27,30,31,38,39]. This finding confirms what is already known on the natural history of HPV infection, which is characterized by higher infection rates after sexual initiation. In agreement with published data $[2,40]$, the age adjusted HPV prevalence rate in the Aboriginal group was higher than that in the nonAboriginal group. Inconsistent trends in HPV prevalence by age were noted in older women, with a decrease or plateau of HPV prevalence among the non-Aboriginal group, whereas the Aboriginal group showed an increase of HPV prevalence (U-shaped age-specific HPV prevalence distribution). This has been observed in the other studies in Canada [2,15,30,31] and from Costa Rica and other Latin American countries [41,42], with the lowest prevalence among the age group 40-49. However, from most of the European literature, with the exception of the former Soviet Union [33], a decrease in HPV prevalence after age 20 and a levelling off after age 45, has been reported [25,26,28,42]. Further study needs to appreciate what role that social, cultural and lifestyle factors, as well as environmental determinants such as access to care may play in explaining this difference in age distribution.

Noteworthy is that, despite the difference in prevalence of HPV types and cytological abnormalities between Aboriginal and Non-Aboriginal women, the proportion of HPV 16/18 in high grade lesion is about $50 \%$ in both groups. This is very similar to the average proportion of HPV 16/18 in HSIL in North America and worldwide [13]. Since HSILs are the precursors of invasive cancer, these results suggest that the current HPV vaccines should be equally applicable to Aboriginal and Non-Aboriginal women.

Currently routine Pap testing is one of the pillars to prevent cervical cancer. Other studies have found similar Pap test abnormality rates [2,30]. HPV prevalence was higher in those women aged $<30$ than in older women across the spectrum of abnormal Pap results. This is consistent with reports showing that HPV infection is common in young women and most often transient [43-46]. It is expected that women aged 30 years and older experience more persistent HR infections than younger women and that HPV-DNA testing would be able to triage this group for further follow-up.

Among participants with a normal pap test result, 26\% of any type HPV infection among the Aboriginal group and $15 \%$ among the non-Aboriginal women (Table 3) translated into a 28 times higher risk of cervical abnormality than those with HPV negative (Table 4). By the same token, among 5.4\% of the Aboriginal women and $3.4 \%$ of the non-Aboriginal women with both normal Pap test results and HPV 16/18 infection, they have a 50 times higher risk of cervical abnormality than those who are HPV negative. Interestingly, similar to our previous NWT report [47], results seem to indicate an 
additive risk model for multiple HPV infections. This information may be useful in considering HPV testing in cervical cancer screening programs in Northern Canada.

There are potential limitations in the study. Firstly, no PCR protocol is ideal for all types of HPV detection. Any of the above comparisons in prevalence rates must be taken with caution as we have used the most recent IARC classification for HR HPV and a novel (Luminex) detection method as sensitive as Linear Array but able to detect more types than other previously reported technologies such as GP5+/6+, Elisa, or Hybrid Capture [17,18]. Secondly, this study represents HPV infection at various time points in the different regions, and does not represent the proportion of women at risk for disease or cancer related to HPV infection. Of note, there was no full regional coverage of the targeted populations during the study period. Different regions had different recruitment methods and therefore rates. Due to an "opt-in" process, the coverage for the Yukon sites lower than the other regions, and one thus should be cautious in interpreting the prevalence rates of the study population for Yukon. In addition, the Aboriginal status was not available in Labrador. To estimate HPV prevalence by ethnic group in the entire North in Canada, we used residence for Aboriginal or non-Aboriginal area instead as the purpose of the study was to understand the severity of HPV prevalence in Northern Canada and each northern region. Although we provided both crude rates and age adjusted rates for HPV infection, it still needs to be cautious to make comparison by region due to substantially different data collection processes. Finally, it's worth noting that routine screening is not recommended by standard guidelines for young women aged 14-18. In addition Pap screening is not mandatory for anyone; e.g., NWT has their own guidelines [48] and Yukon follows a guideline from British Columbia. Therefore, there may be a selection bias toward the young age group in data analysis. Nevertheless, the overall analysis was conducted with and without the 14-18 years age group and the results remained similar. We suspect also that there may be a potential bias affecting participation by Aboriginal versus non-Aboriginal people.

\section{Conclusions}

In Northern Canada, the prevalence of HPV infection was higher than other Canadian areas and varied by region. Between the Aboriginal and the non-Aboriginal group, the age specific distribution rates of HPV infections appear to be different; however, the effect of HPV infection to cervical dysplasia was similar. The relatively high prevalence of HR-HPV other than HPV 16/18, in particular among the Aboriginal group, call for further study to understand the impact of specific predictors [49]. This study provides baseline information on HPV prevalence that may assist in surveillance and evaluation systems to track and assess HPV vaccine programs.

\section{Abbreviations}

AAPR: Age-adjusted prevalence rate; ASC-H: Atypical squamous cells where HSIL could not be excluded; ASC-US: Atypical squamous cells of undetermined significance; ARF: Attributable risk fraction; Cl: Confidence interval; HPV: Human papillomavirus; HPV_m: Two or more types of HPV infection; HPV_s: a Single type of HPV infection; HR: High risk; HR_m: Two or more types of high risk infection; HR_s: a Single type of high risk infection; HSIL: High-grade squamous intraepithelial lesion; LR: Low risk;

LSIL: Low-grade squamous intraepithelial lesion; NML: National microbiology laboratory; NWT: Northwest territories; OR: Odds ratio; Pap: Papanicolaou test; PAR: Population attributable risk fraction; PCR: Polymerase chain reaction.

\section{Competing interests}

There is no conflict of interest related to this work from any author.

\section{Authors' contributions}

YJ: linked the datasets, analyzed the data, drafted the manuscript. PB: participated in the data collection, data analysis and results interpretation. AS: carried out all HPV DNA typing tests, revised the manuscript and helped to finalize the manuscript. YM: designed the study and made the substantial contributions to interpretation of data. YAL: involved in the majority of the project management work for NWT and Yukon. JAL: involved in data interpretation and helped revise the manuscript. SC: carried out the data collection in NWT and involved in the results discussion. AC: carried out the study in NWT site and involved in the results discussion. KK: carried out the study in NWT site and involved in the data collection and linkage. BH: carried out the data collection in Yukon site and provided with the critical review of the results. IS: initiated and managed the data collection in Nunavut. MA-R: initiated and carried out the data collection in Labrador-Grenfell Health, and involved in the results discussion. GJ: carried out Pap test for samples from NWT and Nunavut. JL: carried out Pap test for samples from Yukon. SR: carried out Pap test for samples from Labrador and involved in the results discussion. TW: involved in the data collection in NWT, Nunavut, and Labrador. AD: participated in the analysis of data and the critical review of the results. GJ: participated in conducting HPV type-specific surveillance and linkages to cytology results in Nunavut, involved in data interpretation and helped revise the manuscript. ST: involved in data interpretation and helped revise the manuscript. HM: performed the study and revised the manuscript. All authors read and approved the final manuscript.

\section{Acknowledgments}

This study was supported by International Polar Year Initiative and Public Health Agency of Canada. We thank all the participants as well as physicians and nurses in the three Territories and Labrador health region in this study.

\section{Funding}

Supported by the Government of Canada International Polar Year Program and Public Health Agency of Canada.

\section{Author details}

${ }^{1}$ Science Integration Division, Public Health Agency of Canada (PHAC), 785 Carling Ave., Ottawa, ON K1A 0K9, Canada. ${ }^{2}$ Division of Clinical Epidemiology, McGill University Health Center, 687 Des Pins West, Montreal, QC H3A 1A1, Canada. ${ }^{3}$ National Microbiology laboratory, PHAC, 1015 Arlington St., Winnipeg, MB R3E 3R2, Canada. ${ }^{4}$ Centre for Immunization and Respiratory Infectious Diseases, PHAC, 130 Colonnade Rd, Ottawa, ON K1A 0K9. Institute for Circumpolar Health Research, 3506 MacDonald Road, Yellowknife, NWT X1A 3X7, Canada. ${ }^{6}$ Department of Health \& Social Services, CST-6, Yellowknife, NWT X1A 2L9, Canada. ${ }^{7}$ Department of Health \& Social Services, \#4 Hospital Road, Whitehorse, YK Y1A 3H8, Canada. ${ }^{8}$ Nunavut Department of Health and Social Services, Nunavut (at the time of the data collection) and currently with Health Canada, Nunavut, Canada. 'Labrador-Grenfell Health, Happy Valley-Goose Bay NL, Canada. ${ }^{10}$ Dynacare Kasper Medical Laboratories, 200.10150 102 Street, Edmonton, AB T5J 5E2, Canada. "11Provincial Health Services Authority Laboratories, British Columbia Cancer Agency, 686 West Broadway, Vancouver, BC V5Z 1G1, Canada. ${ }^{12}$ Faculty of Medicine, Memorial University, St. John's, NL, Canada. ${ }^{13}$ Centre for Communicable Diseases and Infection Control, PHAC, 200 Eglantine Driveway, Tunney's Pasture, Ottawa, ON K1A OK9, Canada.

Received: 25 February 2013 Accepted: 3 June 2013

Published: 1 July 2013 


\section{References}

1. Louchini R, Beaupre M: Cancer incidence and mortality among Aboriginal people living on reserves and northern villages in Quebec, 1988-2004. Int J Circumpolar Health 2008, 67(5):445-451.

2. Hamlin-Douglas LK, Coutlee F, Roger M, Franco EL, Brassard P: Prevalence and age distribution of human papillomavirus infection in a population of Inuit women in Nunavik. Quebec. Cancer Epidemiol Biomarkers Prev 2008, 17(11):3141-3149.

3. Young TK, Kliewer E, Blanchard J, Mayer T: Monitoring disease burden and preventive behavior with data linkage: cervical cancer among Aboriginal people in Manitoba. Canada. Am J Public Health 2000, 90(9):1466-1468.

4. Circumpolar Inuit Cancer Review Working Group: Cancer among the circumpolar Inuit, 1989-2003 II. paterns and trends circumpolar inuit. Int J Circumpolar Health 2008, 67(5):408-420.

5. Annual Population Estimates by Community \& Other Characteristics of the Northwest Territories: NWT Bureau of Statistics. 2009. http://www.statsnwt. ca/population/population-estimates/

6. Nunavut Census 2006: Statistics Canada Website. http://www12.statcan.ca/ census-recensement/2006/dp-pd/prof/92-591/details/page.cfm?Lang= E\&Geo $1=P R \& C o d e 1=62 \& G e 02=P R \& C o d e 2=62 \&$ Data $=$ Count\&SearchText $=$ Nunavut\&SearchType=Begins\&SearchPR $=01 \& B 1=$ Aboriginal\% 20peoples\&Custom =

7. Labrador Census 2006: Statistics Canada Website. http://www12.statcan.ca/ census-recensement/2006/dp-pd/prof/92-591/details/page.cfm?Lang= E\&Geo $1=C D \& C o d e 1=1010 \& G e 02=P R \&$ Code2 $=10 \&$ Data $=$ Count $\&$ SearchText $=$ Division\%20No.\%2010\&SearchType=Begins\&SearchPR=01\&B1=Aboriginal\% 20peoples\&Custom $=$

8. Yukon Territory Community Profiles from the 2006 Census: Statistics Canada Census Division. http://www12.statcan.gc.ca/census-recensement/2006/dp-pd/ prof/92-591/details/page.cfm?Lang=E\&Geo $1=C D \& C o d e 1=6001 \& G e 02=P R \&$ Code2 $=60 \&$ Data $=$ Count\&SearchText=yukon\&SearchType $=$ Begins\&SearchPR $=$ 01\&B1=All\&Custom=

9. Kjaer SK, Nielsen NH: Cancer of the female genital tract in circumpolar inuit. Acta Oncol 1996, 35(5):581-587.

10. Public Health Agency of Canada: Cervical Cancer Screening in Canada: 1998 Surveillance Report. http://www.phac-aspc.gc.ca/publicat/ccsic-dccuac/ chap_5-eng.php

11. Munoz N, Bosch FX, de SS, Herrero R, Castellsague X, Shah KV, Snijders PJ, Meijer CJ: International Agency for Research on Cancer Multicenter Cervical Cancer Study Group: epidemiologic classification of human papillomavirus types associated with cervical cancer. N Engl I Med 2003, 348(6):518-527.

12. Walboomers JM, Jacobs MV, Manos MM, Bosch FX, Kummer JA, Shah KV, Snijders PJ, Peto J, Meijer CJ, Munoz N: Human papillomavirus is a necessary cause of invasive cervical cancer worldwide. J Pathol 1999 Sep, 189(1):12-19.

13. Smith JS, Lindsay L, Hoots B, Keys J, Franceschi S, Winer R, Clifford GM: Human papillomavirus type distribution in invasive cervical cancer and high-grade cervical lesions: a meta-analysis update. Int J Cancer 2007, 121(3):621-632. http://www.ncbi.nlm.nih.gov/pubmed/17405118

14. WHO/ICO Information Centre on HPV and Cervical Cancer (HPV Information Centre): Human Papillomavirus and Related Cancers: Summary Report Update 2010 Sep. 15. http://apps.who.int/hpvcentre/statistics/dynamic/ico/ country_pdf/CAN.pdf?CFID=7515274\&CFTOKEN=87500998

15. Healey SM, Aronson KJ, Mao Y, Schlecht NF, Mery LS, Ferenczy A, Franco EL Oncogenic human papillomavirus infection and cervical lesions in Aboriginal women of Nunavut. Canada. Sex Transm Dis 2001, 28(12):694-700.

16. Canadian Partnership Against Cancer: 2010 System Performance Report. http://www.partnershipagainstcancer.ca/wp-content/uploads/ system_performance_2010_EN.pdf

17. Zubach V, Smart G, Ratnam S, Severini A: Novel microsphere-based method for detection and typing of 46 mucosal human papillomavirus types. J Clin Microbiol 2012, 50(2):460-464

18. Rebbapragada A, Perusini S, Di Prima A, Salit I, Goleski V, Ratnam S, et al: Evaluation of Test Performance Characteristics and Operational Parameters of 5 HPV genotyping assays. Montreal, Canada: In proceedings of the 26th International Papillomavirus Conference; 2010.

19. Bouvard V, Baan R, Straif K, Grosse Y, Secretan B, El Ghissassi F, benbrahim-Tallaa L, Guha N, Freeman C, Galichet L, Cogliano V, WHO International Agency for Research on Cancer Monograph Working Group: A review of human carcinogens--Part B: biological agents. Lancet Oncol 2009, 10:321-322.
20. Solomon D, Davey D, Kurman R, Moriarty A, O'Connor D, Prey M, RAAB S, Sherman M, Wilbur D, Wright T Jr, Young N, Forum Group Members; Bethesda 2001 Workshop: The 2001 Bethesda System: terminology for reporting results of cervical cytology. JAMA 2002, 287(16):2114-2119.

21. Apgar BS, Zoschnick L, Wright TC Jr: The 2001 Bethesda System terminology. Am Fam Physician 2003, 68(10):1992-1998.

22. Fleiss $\mathrm{J} L$ : Inference about population attributable risk from cross-sectional studies. Am J Epidemiol 1979, 110(2):103-104. http://www.ncbinlm.nih.gov/pubmed/313702

23. Newcombe RG: Two-sided confidence intervals for the single proportion: comparison of seven methods. Stat Med 1998, 17(8):857-872. http://www3.interscience.wiley.com/cgi-bin/fulltext/3156/PDFSTART

24. Clifford GM, Gallus S, Herrero R, Munoz N, Snijders PJ, Vaccarella S, Anh PT, Ferreccio C, Hieu NT, Matos E, Molano M, Rajkumar R, Ronco G, de Sanjosé S, Shin HR, Sukvirach S, Thomas JO, Tunsakul S, Meijer CJ, Franceschi S, IARC HPV Prevalence Surveys Study Group: Worldwide distribution of human papillomavirus types in cytologically normal women in the International Agency for Research on Cancer HPV prevalence surveys: a pooled analysis. Lancet 2005, 366(9490):991-998.

25. Ronco G, Ghisetti V, Segnan N, Snijders PJ, Gillio-Tos A, Meijer CJ, Merletti F, Franceschi S: Prevalence of human papillomavirus infection in women in Turin. Italy. Eur J Cancer 2005, 41(2):297-305.

26. Kitchener HC, Almonte M, Wheeler P, Desai M, Gilham C, Bailey A, Sargent A, Peto J, ARTISTIC Trial Study Group: HPV testing in routine cervical screening: cross sectional data from the ARTISTIC trial. Br J Cancer 2006, 95(1):56-61.

27. Lin H, Ma YY, Moh JS, Ou YC, Shen SY, Changchien CC: High prevalence of genital human papillomavirus type 52 and 58 infection in women attending gynecologic practitioners in South Taiwan. Gynecol Oncol 2006, 101(1):40-45.

28. Kjaer SK, Breugelmans G, Munk C, Junge J, Watson M, Iftner T: Population-based prevalence, type- and age-specific distribution of HPV in women before introduction of an HPV-vaccination program in Denmark. Int J Cancer 2008, 123(8):1864-1870.

29. Dunne EF, Unger ER, Sternberg M, McQuillan G, Swan DC, Patel SS, Markowitz LE: Prevalence of HPV infection among females in the United States. JAMA 2007, 297(8):813-819.

30. Moore RA, Ogilvie G, Fornika D, Moravan V, Brisson M, Amirabbasi-Beik M, Kollar A, Burgess T, Hsu R, Towers L, Lo J, Matisic J, Brooks-Wilson A: Prevalence and type distribution of human papillomavirus in 5,000 British Columbia women-implications for vaccination. Cancer Causes Control 2009 Oct, 20(8):1387-1396.

31. Sellors JW, Mahony JB, Kaczorowski J, Lytwyn A, Bangura H, Chong S, Lorincz A, Dalby DM, Janjusevic V, Keller JL: Prevalence and predictors of human papillomavirus infection in women in Ontario, Canada. Survey of HPV in Ontario Women (SHOW) Group. CMAJ 2000, 163(5):503-508.

32. Pannier-Stockman C, Segard C, Bennamar S, Gondry J, Boulanger JC, Sevestre H, Castelain S, Duverlie G: Prevalence of HPV genotypes determined by PCR and DNA sequencing in cervical specimens from French women with or without abnormalities. J Clin Virol 2008, 42(4):353-360.

33. Kulmala SM, Shabalova IP, Petrovitchev N, Syrjanen KJ, Gyllensten UB, Syrjanen SM: Prevalence of the most common high-risk HPV genotypes among women in three new independent states of the former Soviet Union. J Med Virol 2007, 79(6):771-781.

34. Nielsen A, Kjaer SK, Munk C, Iftner T: Type-specific HPV infection and multiple HPV types: prevalence and risk factor profile in nearly 12,000 younger and older Danish women. Sex Transm Dis 2008, 35(3):276-282.

35. Tricco AC, Ng CH, Gilca V, Anonychuk A, Pham B, Berliner S: Canadian oncogenic human papillomavirus cervical infection prevalence: systematic review and meta-analysis. BMC Infect Dis 2011, 11:235.

36. Naucler P, Ryd W, Tomberg S, Strand A, Wadell G, Hansson BG, Rylander E, Dillner J: HPV type-specific risks of high-grade CIN during 4 years of follow-up: a population-based prospective study. Br J Cancer 2007, 97(1):129-132.

37. Dunne EF, Sternberg M, Markowitz LE, McQuillan G, Swan D, Patel S, Unger ER: Human papillomavirus (HPV) $6,11,16$, and 18 prevalence among females in the United States-National Health And Nutrition Examination Survey, 2003-2006: opportunity to measure HPV vaccine impact? I Infect Dis 2011, 204(4):562-565.

38. Rama CH, Roteli-Martins CM, Derchain SF, Longatto-Filho A, Gontijo RC, Sarian LO, Syrjänen K, Aldrighi JM: Prevalence of genital HPV infection among women screened for cervical cancer. Rev Saude Publica 2008, 42(1):123-130 
39. Coupe VM, Berkhof J, Bulkmans NW, Snijders PJ, Meijer CJ: Age-dependent prevalence of 14 high-risk HPV types in the Netherlands: implications for prophylactic vaccination and screening. Br J Cancer 2008, 98(3):646-651.

40. Young TK, McNicol P, Beauvais J: Factors associated with human papillomavirus infection detected by polymerase chain reaction among urban Canadian Aboriginal and non-Aboriginal women. Sex Transm Dis 1997, 24(5):293-298.

41. Herrero R, Castle PE, Schiffman M, Bratti MC, Hildesheim A, Morales J, Alfaro M, Sherman ME, Wacholder S, Chen S, Rodriguez AC, Burk RD: Epidemiologic profile of type-specific human papillomavirus infection and cervical neoplasia in Guanacaste. Costa Rica. J Infect Dis 2005, 191(11):1796-1807.

42. Franceschi S, Herrero R, Clifford GM, Snijders PJ, Arslan A, Anh PT, Bosch FX, Ferreccio C, Hieu NT, Lazcano-Ponce E, Matos E, Molano M, Qiao YL, Rajkumar R, Ronco G, de Sanjosé S, Shin HR, Sukvirach S, Thomas JO, Meijer CJ, Muñoz N: Variations in the age-specific curves of human papillomavirus prevalence in women worldwide. Int J Cancer 2006, 119(11):2677-2684.

43. Koshiol J, Lindsay L, Pimenta JM, Poole C, Jenkins D, Smith JS: Persistent human papillomavirus infection and cervical neoplasia: a systematic review and meta-analysis. Am J Epidemiol 2008, 168(2):123-137. http://www.ncbi.nlm.nih.gov/pubmed/18483125

44. Kulasingam SL, Hughes JP, Kiviat NB, Mao C, Weiss NS, Kuypers JM, Koutsky LA: Evaluation of human papillomavirus testing in primary screening for cervical abnormalities: comparison of sensitivity, specificity, and frequency of referral. JAMA 2002, 288(14):1749-1757.

45. Giuliano AR, Papenfuss M, Abrahamsen M, Denman C, De Zapien JG, Henze JL, Ortega L, de Galaz EM B, Stephan J, Feng J, Baldwin S, Garcia F, Hatch K: Human papillomavirus infection at the United States-Mexico border: implications for cervical cancer prevention and control. Cancer Epidemiol Biomarkers Prev 2001, 10(11):1129-1136.

46. Peyton $C L$, Gravitt PE, Hunt WC, Hundley RS, Zhao M, Apple RJ, Wheeler CM: Determinants of genital human papillomavirus detection in a US population. J Infect Dis 2001, 183(11):1554-1564.

47. Jiang Y, Brassard P, Severini A, Goleski V, Santos M, Leamon A, Chatwood S, Lys C, Johnson G, Wong T, Kotaska A, Kandola K, Mao Y: Type-specific prevalence of human papillomavirus infection among women in the Northwest Territories, Canada. J Infect Public Health 2011, 4(5-6):219-227.

48. NWT Cervical Cancer Screening Clinical Practice Guidelines. 2010. http://www.hss.gov.nt.ca/sites/default/files/page_95_nwt_cervical_cancer_ screening_guidelines.pdf

49. Brassard P, Jiang Y, Severini A, Goleski V, Santos M, Leamon A, Chatwood S, Lys C, Johnson G, Wong T, Rebibo D, Kotaska A, Kandola K, Morrison H, Mao Y: Factors associated with human papillomavirus infection among women in the Northwest Territories. Can J Public Health 2012, 103(4):282-287.

doi:10.1186/1750-9378-8-25

Cite this article as: Jiang et al.: The prevalence of human papillomavirus and its impact on cervical dysplasia in Northern Canada. Infectious Agents and Cancer 2013 8:25.

\section{Submit your next manuscript to BioMed Central and take full advantage of:}

- Convenient online submission

- Thorough peer review

- No space constraints or color figure charges

- Immediate publication on acceptance

- Inclusion in PubMed, CAS, Scopus and Google Scholar

- Research which is freely available for redistribution 